TAO, Vol. 15, No. 1, 61-73, March 2004

\title{
Centroid Moment Tensor Solutions for Taiwan Earthquakes of the WWSSN Era (1963-1975)
}

\author{
Po-Fei Chen ${ }^{1, *}$, Göran Ekström ${ }^{2}$, and Emile A. Okal ${ }^{1}$ \\ (Manuscript received 12 November 2003, in final form 13 January 2004)
}

\begin{abstract}
We use analog seismograms to invert seventeen new centroid moment tensor solutions for shallow earthquakes in the vicinity of Taiwan during the period 1963-1975, with the exact same algorithm used to produce the Harvard catalog for modern events recorded on digital seismographs. The average rate of moment release featured by the 17 events is double that of the modern seismicity of the study area, as expressed in the Harvard catalog, and if the 1999 Chi-chi earthquake and its aftershocks are discarded. Significant deviations in geometry are found between some of our solutions and focal mechanisms previously obtained for the same events by a variety of authors. Our study provides a more complete dataset of focal solutions in Taiwan for future analysis of the regional tectonic strain release.
\end{abstract}

(key words: Harvard CMT catalog, Taiwan earthquakes, WWSSN)

\section{INTRODUCTION}

In this study, we systematically invert Centroid Moment Tensors (CMT) for a series of 17 shallow Taiwan earthquakes (0-70 km) from 1963 to 1975 . The primary purpose of this study is to extend the time span of the Harvard CMT catalog in order to achieve a more complete dataset for the study of this highly active region. The CMT algorithm, implemented by the seismology research group at Harvard University, has created the most consistent and complete dataset of focal solutions available for use in seismological research. We recall that the term "centroid" refers to the simultaneous inversion of source location, origin time and focal geometry. We refer to Dziewonski et al. (1981) for a detailed description of the original algorithm, and to Dziewonski and Woodhouse (1983) and Woodhouse and Dziewonski (1984)

1 Department of Geological Sciences, Northwestern University, Evanston, IL 60201, USA

2 Department of Earth and Planetary Sciences, Harvard University, Cambridge, MA 02138, USA

* Corresponding author address: Prof. Po-Fi Chen, Institute of Earth Sciences, Academia Sinica, Taipei, Taiwan, ROC; E-mail: bob@earth.sinica.edu.tw 
for later refinements of its methodology, such as the incorporation of mantle surface waves and the use of a laterally heterogeneous Earth model.

Any catalog can only be as good as it is complete. In this respect, the Harvard catalog, which begins in 1977 with the advent of reliable data from digital seismic networks, may suffer from its relative youth, as compared with the typical duration of earthquake cycles. The latter are both poorly known and highly variable from one region to the next, but most estimates would suggest that the CMT dataset is indeed undersampled in time. This is probably best illustrated on a worldwide scale by the mere fact that the largest earthquake in the catalog, the 2001 Peruvian event, remains dwarfed by at least four earthquakes from the 1960-1975 time window (including the 1960 Chilean earthquake, which featured a moment at least 50 times larger), and by three more from the previous decade (Okal 1992). This potential limitation motivated the efforts of Huang et al. (1994, 1997), Chen et al. (2001) and Chen (2002), who expanded the worldwide dataset of CMT solutions for deep and intermediate-depth earthquakes backward in time, using analog seismological data. The present study follows the same philosophy and procedures and expands the regional dataset of shallow earthquakes $(0-70 \mathrm{~km})$ in the vicinity of Taiwan over the lifetime of the WWSSN (1963-1975). We do not consider the year 1976 which was investigated separately by Ekström and Nettles (1997); their study did not produce any new solutions in our study area.

\section{DATASET AND METHODOLOGY}

We targeted for inversion all events occurring in 1963-1975, within the region limited by $21^{\circ} \mathrm{N}, 26^{\circ} \mathrm{N}, 119^{\circ} \mathrm{E}$ and $123^{\circ} \mathrm{E}$, with a reported depth no greater than $70 \mathrm{~km}$, and at least one reported magnitude (most often $m_{b}$ ) $\geq 5$.8. Our experience has shown that events below that threshold generally cannot be inverted reliably from analog records. These criteria produced 26 target earthquakes. Visual inspections of WWSSN records revealed no clear signals for 8 events, which were discarded. For the remaining 18 events, records from an average of 6 stations well distributed in azimuth were printed, and a processing window consisting of generalized body waves ( $\mathrm{P}$ group, $\mathrm{S}$ group, and mantle reverberations such as PS, SS, etc.) was isolated, lasting from $2 \mathrm{mn}$ before the $\mathrm{P}$ arrival to $2 \mathrm{mn}$ after the arrival of Love waves. Threecomponent records were hand-digitized and equalized to a common sampling interval of $1 \mathrm{~s}$, identical to that used on long-period channels of present-day digital networks. The inversion then proceeded along the exact same algorithm implemented for routine processing of modern events at Harvard University, including the criteria for assessing the quality of a solution and its eventual acceptance into, or rejection from, the CMT database. Only one event was discarded (on 23 September 1972), leaving a total of 17 new solutions.

Tables 1 and 2 and Fig. 1 present our dataset in the familiar format of the quarterly reports of the Harvard group. The solutions are regrouped in map form on Fig. 2. The left part of Table 1 displays source parameters of the centroid moment tensor solution. The perturbations $\delta t_{0}$, $\delta \lambda_{0}, \delta \phi_{0}$ and $\delta h_{0}$ are deviations with respect to the NEIC source parameters. In the case of a few smaller earthquakes, we had to keep the epicenter or the centroid depth (or both) constrained during the inversion to obtain a stable solution; the relevant parameters $(\lambda, \phi$ and/or 
Table 1. Centroid coordinates and parameters derived from moment tensor solutions for 17 Taiwan earthquakes of 1963-1975.

\begin{tabular}{|c|c|c|c|c|c|c|c|c|c|c|c|c|c|c|c|c|c|c|c|c|c|c|c|c|c|c|c|c|c|}
\hline \multirow{3}{*}{ No. } & \multicolumn{13}{|c|}{ Centroid parameters } & \multirow{3}{*}{\begin{tabular}{|} 
Thalf \\
Drtn
\end{tabular}} & \multirow{3}{*}{\begin{tabular}{|c|} 
Scale \\
Factor \\
$10^{-e x}$
\end{tabular}} & \multicolumn{8}{|c|}{ Principal Axes } & \multicolumn{6}{|c|}{ Best Double-Couple } \\
\hline & & Date & & 1 & & ime & $T$ & Latitude & 1 & Lon & & Depth & & & & & axis & & $\overline{\mathrm{N} \text {-axis }}$ & & $P-2$ & -axis & & & & ane 1 & $\mathrm{Pla}$ & lane 2 & \\
\hline & $\mathrm{D}$ & $\mathbf{M}$ & $\mathrm{Y}_{1}$ & $\mathrm{~h}$ & $\mathbf{m}$ & 3 & $\delta t_{0} \mid$ & $i$ & $\delta \lambda_{0}$ & $\varphi$ & $\delta \varphi_{0}$ & h & $\delta h_{0}$ & & & & & $\sigma$ & $\delta$ & 5 & $\sigma$ & & & & & 2 & & $\theta$ & \\
\hline 1 & 13 & 21 & 1963 & 8 & 50 & $1 \pm 0$. & 5.6 & $17 \pm .04$ & -0.33 & 1.69 & -0.41 & $6 \pm 3.2$ & 12.4 & 8.9 & 26 & 135 & 56307 & \begin{tabular}{l|l|}
7 & 0.81
\end{tabular} & 125 & \begin{tabular}{|c|c|}
79 \\
.
\end{tabular} & -7.55 & 22 & & 7.1 & 308 & 143 & & 72 & \\
\hline 2 & & 11 & 1964 & 12 & 4 & 5 & 15. & & & & & & & & & & 58186 & 6 & 31 & 20 & & & I & & 64 & 45 & & 5 & 12 \\
\hline 3 & & 4 & & 22 & 15 & & & & & & & & & & & & & & 1 & & & t & & & & & & & \\
\hline 4 & 17 & 5 & 1965 & & 19 & 3 & 2. & & & & & & -13.2 & & & & 31 & .19 & 954 & 275 & & 17 & 161 & & & & & & \\
\hline & & 3 & 1966 & 16 & 31 & & 13.4 & 24.2 & & & & & -0.6 & & & & 35356 & 0.59 & 9 & & 30 & 13 & & & & & & & \\
\hline 6 & 20 & 3 & & 0 & 4 & & & & & & & & & & & & $42 \quad 1$ & .38 & 8 & & & & & & & & & & \\
\hline 7 & 5 & 5 & & 14 & 21 & & & & $030 \div-1$ & & & & & & & & 31 & .31 & 158 & 199. & -2.72 & 5 & 100 & .9 & 48 & 64 & & & \\
\hline 8 & 25 & 10 & & $\because$ & 59 & & & & & & & & -16.3 & & & & $\begin{array}{ll}57 & 26\end{array}$ & & 230 & & & 11 & & & & & & & \\
\hline & 14 & 11 & & 7 & 58 & & 4. & & 0.07 & & -0.0 & & -6.8 & & & 87 & $\begin{array}{ll}78 & 251\end{array}$ & -0.06 & 60 & 21 & $\mid-2.72$ & 9 & 2 & 2.8 & 2113 & 3 & & 55 & \\
\hline & 4 & 2 & 1972 & 3 & 16 & 5 & 8.6 & & -0.10 & 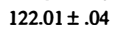 & -0.0 & 6 & 21.3 & & & 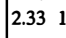 & - & $\begin{array}{lll}5 & 0.37\end{array}$ & 73 & 343 & -2.69 & 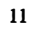 & 3 & 2.5 & 249 & 73 & & 89 & \\
\hline & & 11 & & & & & & & & & & & & & & & & & & & & & & & & & & & \\
\hline & & 1 & & 10 & 49 & & & & & & $-c-c-c$ & & & & & & & & & & & & & & & & & & \\
\hline & & 4 & & & 57 & & & & -0 & & & & -1 & & & & 59 & & 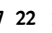 & & & 2 & & & & & & & \\
\hline & 26 & 9 & & 15 & 57 & & & & & & & & & & & & & & & & & & & & & & & & \\
\hline & 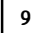 & 11 & & 1.0 & . & & 3 & & & & & & & & & & 55 & & 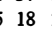 & 0. & & 29 & & & & 30 & & & \\
\hline & & 3 & & 7 & 32 & & 1. & & & & & & & & & & & & & 22 & 98 & & & & & 5 & 2378 & & \\
\hline & & 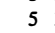 & & 10 & & $51.5 \pm 0.3$ & 3.0 & 26.101 .04 & & $122.30 \pm .00$ & .J & $21.3 \pm 0.0$ & & & & & & & & & & & & & & & & & \\
\hline
\end{tabular}

Table 2. Elements of the moment tensors obtained in CMT inversions.

\begin{tabular}{|c|c|c|c|c|c|c|c|}
\hline No. & Scale & \multicolumn{6}{|c|}{ Elements of Moment Tensor } \\
\hline & $10^{a x}$ & $M_{r}$ & $M_{\theta 0}$ & $M_{m}$ & $M_{r o}$ & $M_{n}$ & $M_{p e}$ \\
\hline 1 & 26 & $3.63 \pm 0.17$ & $-5.66 \pm 0.21$ & $2.02 \pm 0.20$ & $4.60 \pm 0.53$ & $2.20 \pm 0.32$ & $0.92 \pm 0.19$ \\
\hline 2 & 25 & $4.77 \pm 0.26$ & $1.96 \pm 0.29$ & $-6.73 \pm 0.26$ & $-2.49 \pm 0.75$ & $-0.65 \pm 1.00$ & $-2.49 \pm 0.31$ \\
\hline 3 & 25 & $-1.88 \pm 0.07$ & $-0.03 \pm 0.09$ & $1.90 \pm 0.09$ & $0.34 \pm 0.19$ & $-0.49 \pm 0.26$ & $0.32 \pm 0.10$ \\
\hline 4 & 26 & $0.13 \pm 0.03$ & $-0.68 \pm 0.04$ & $0.55 \pm 0.05$ & $0.55 \pm 0.04$ & $-0.49 \pm 0.03$ & $-0.72 \pm 0.05$ \\
\hline 5 & 27 & $0.45 \pm 0.14$ & $1.73 \pm 0.12$ & $-2.18 \pm 0.17$ & $1.66 \pm 0.18$ & $0.50 \pm 0.10$ & $0.04 \pm 0.14$ \\
\hline 6 & 25 & $1.01 \pm 0.14$ & $1.35 \pm 0.20$ & $-2.36 \pm 0.16$ & $1.57 \pm 0.24$ & $0.10 \pm 0.24$ & $-0.14 \pm 0.15$ \\
\hline 7 & 25 & $0.57 \pm 0.13$ & $2.02 \pm 0.19$ & $-2.59 \pm 0.17$ & $1.51 \pm 0.25$ & $0.04 \pm 0.22$ & $-0.70 \pm 0.15$ \\
\hline 8 & 26 & $1.49 \pm 0.09$ & $0.63 \pm 0.13$ & $-2.12 \pm 0.10$ & $0.73 \pm 0.09$ & $-0.89 \pm 0.09$ & $-0.57 \pm 0.10$ \\
\hline 9 & 25 & $2.59 \pm 0.14$ & $-0.41 \pm 0.14$ & $-2.18 \pm 0.15$ & $-0.04 \pm 0.34$ & $0.93 \pm 0.42$ & $-0.94 \pm 0.14$ \\
\hline 10 & 26 & $0.35 \pm 0.05$ & $1.46 \pm 0.07$ & $-1.81 \pm 0.08$ & $-0.16 \pm 0.15$ & $0.72 \pm 0.18$ & $-1.76 \pm 0.07$ \\
\hline 11 & 27 & $-0.05 \pm 0.05$ & $0.74 \pm 0.04$ & $-0.69 \pm 0.07$ & $-0.38 \pm 0.11$ & $0.59 \pm 0.13$ & $-0.80 \pm 0.05$ \\
\hline 12 & 25 & $0.96 \pm 0.07$ & $-1.45 \pm 0.09$ & $0.49 \pm 0.09$ & $3.09 \pm 0.42$ & $0.98 \pm 0.19$ & $-0.13 \pm 0.08$ \\
\hline 13 & 26 & $2.23 \pm 0.08$ & $-2.10 \pm 0.09$ & $-0.13 \pm 0.08$ & $2.43 \pm 0.38$ & $-0.71 \pm 0.22$ & $-1.22 \pm 0.09$ \\
\hline 14 & 25 & $0.70 \pm 0.10$ & $-0.70 \pm 0.12$ & $0.00 \pm 0.09$ & $2.24 \pm 0.70$ & $-0.61 \pm 0.24$ & $-1.73 \pm 0.10$ \\
\hline 15 & 25 & $0.81 \pm 0.08$ & $-0.43 \pm 0.11$ & $-0.38 \pm 0.08$ & $1.39 \pm 0.18$ & $-0.15 \pm 0.15$ & $-0.48 \pm 0.08$ \\
\hline 16 & 26 & $-0.19 \pm 0.03$ & $1.08 \pm 0.04$ & $-0.89 \pm 0.04$ & $-0.19 \pm 0.08$ & $0.02 \pm 0.08$ & $-0.44 \pm 0.05$ \\
\hline 17 & 25 & $-1.43 \pm 0.14$ & $3.86 \pm 0.17$ & $-2.43 \pm 0.18$ & $-0.64 \pm 0.45$ & $-0.01+0.32$ & $-2.95+0.18$ \\
\hline
\end{tabular}


h) are then shown with a blank entry for precision, and the constrained location is shown as a solid triangle on Fig. 2. Otherwise, on the map, a dashed line links the original epicenter (open triangle) with the inverted centroid (solid circle).

In the right part of Table 1, the parameter "Half Drtn" is the half-duration (in s) of the boxcar source time function, the scaling factor $\left(10^{\mathrm{ex}}\right)$ is the power of 10 scaling (in dyn-cm) the seismic moment $\left(M_{0}\right)$ and the eigenvalues of the moment tensor $(\sigma)$ listed in subsequent columns. The $\mathbf{T}, \mathbf{N}$, and $\mathbf{P}$ axes, given by their dips $[\delta]$ and azimuths $[\xi]$, are the eigenvectors of the largest (positive), intermediate, and smallest (negative) eigenvalues, respectively. The nodal planes of the best-fitting double-couple are given in the convention (strike $\left[\phi_{s}\right], \operatorname{dip}[\theta]$, and rake $[\lambda]$ ) of Aki and Richards (1980). Table 2 lists all individual moment tensor
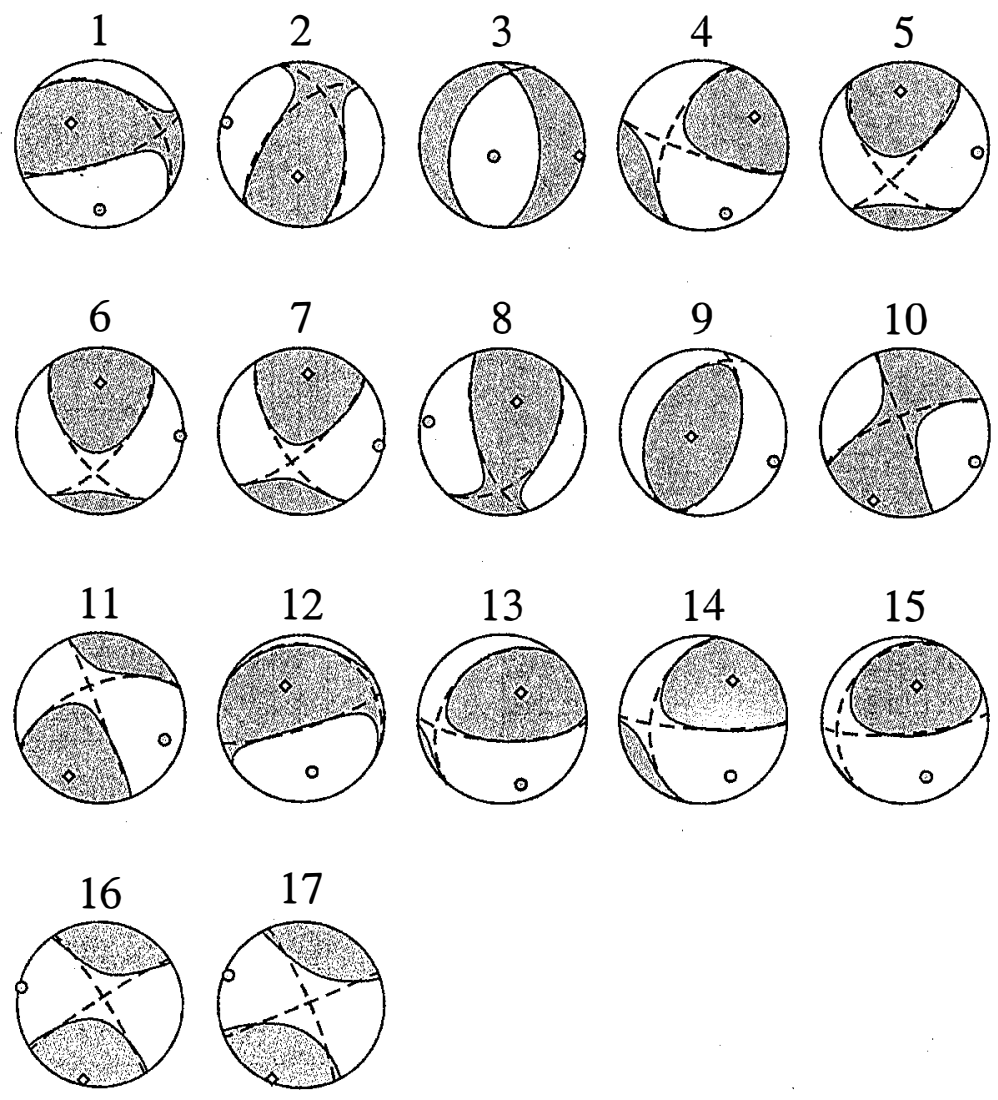

Fig. 1. Equal-area representation of the moment tensors listed in Table 2. Solid lines are the projections of the nodal surfaces of the full moment tensors; dashed lines represent the fault planes of the best-fitting double-couples, as listed in the last columns of Table 1 . The compression and tension axes are shown by solid circles and open squares, respectively. 
components, with the events identified by the same numbers as in Table 1.

Focal mechanisms are given on Fig. 1, with event numbers above each individual "beach ball". The latter represent equal-area projections of the lower focal hemispheres. The solid lines separate shaded quadrants (positive P-wave radiation coefficient, or first motion "up") from open ones (negative or "down") for the full moment tensor solutions, while the dashed lines sketch the best-fitting double-couples.

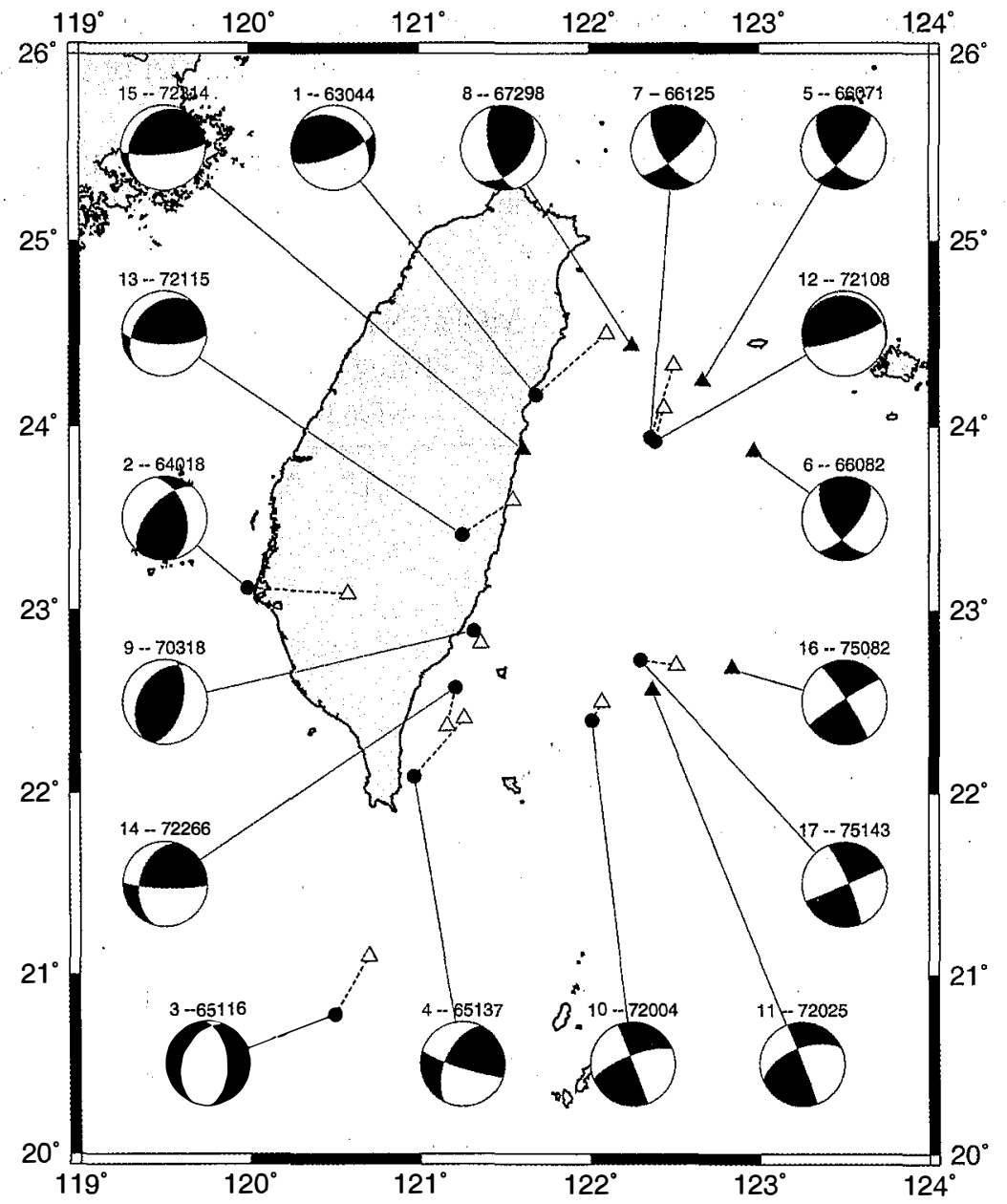

Fig. 2. Map of Taiwan and neighboring areas showing the CMT solutions derived in this study. Events are identified by number and Julian date (YYJJJ). The small dots represent the inverted centroids, linked by dashes to the reference epicenters (open triangles). Solid triangles are published epicenters for those events with constrained locations. 


\section{APPRAISAL OF RESULTS}

\section{Moment release rate and frequency-moment characteristics}

Following Huang and Okal (1998), we first compare the rates of seismic moment release suggested by the present study with those derived from the main 1977-2002 Harvard catalog. Over a 16-yr window, our dataset averages $3.5 \times 10^{26} \mathrm{dyn}-\mathrm{cm} \mathrm{yr}^{-1}$. By comparison, in a similar moment range $\left(M_{0} \geq 1.6 \times 10^{25} \mathrm{dyn}-\mathrm{cm}\right)$, the 1977-2002 Harvard catalog averages a very comparable $3.0 \times 10^{26}$ dyn-cm yr ${ }^{-1}$ in our study area. However, about half of its cumulative moment release involves the 1999 Chi-Chi earthquake and its aftershocks, on a fault system inside central Taiwan, unsampled by our dataset. Thus, in the remainder of the region, our new solutions feature double the release rate of the modern Harvard catalog.

We examine on Fig. 3 the frequency-moment distribution of our dataset. In spite of its relatively small size, we regressed it using the parameter $\beta$, as introduced by Molnar (1979)

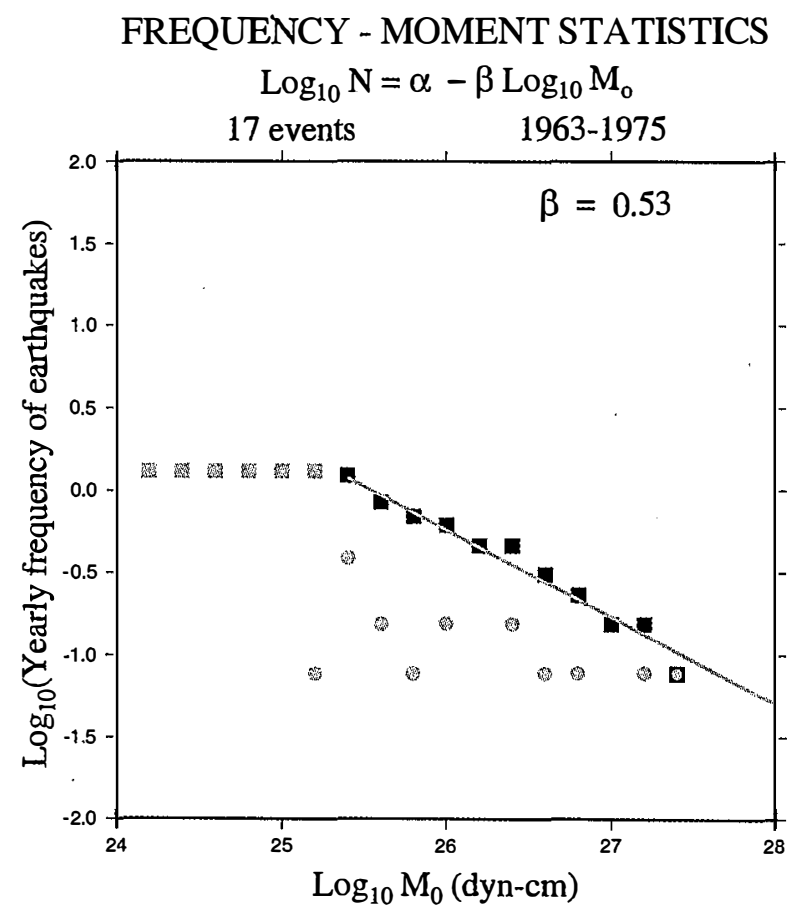

Fig. 3. Gray dots show incremental population of CMT solutions inverted in the present study, binned at intervals of $0.2 \log _{10}$ units. They suggest completeness for $M_{0} \geq 2.5 \times 10^{25} \mathrm{dyn}-\mathrm{cm}$. Solid squares are cumulative populations binned at the same interval. The gray line (with absolute slope $\beta=0.53)$ regresses the cumulative dataset beyond that threshold. 
and further discussed by Okal and Romanowicz (1994) and Okal and Kirby (1995); we estimate the threshold of completeness of the dataset at $M_{0} \geq 2.5 \times 10^{25} \mathrm{dyn}-\mathrm{cm}$. The resulting parameter, $\beta=0.53$, is comparable to its counterpart for the modern Harvard catalog subset in the same geographic and moment windows ( $\beta=0.58$; Fig. 4 ); this consistency in population statistics provides a posteriori support for the completeness of our dataset. However, both $\beta$ values are smaller than the worldwide average of 0.70 (Okal and Romanowicz 1994), or the value ( $\beta=2 / 3$ ) predicted theoretically by Rundle (1989).

\section{Comparison with previous investigations}

A number of previously published (PP) solutions are found in the literature for most of the 17 events studied here. Focal mechanisms based on P-wave first motions are available for Events 1, 3, 4, 8 (Katsumata and Sykes 1969) and 7 (Tsai et al. 1983). Pezzopane and Wesnousky (1989) performed waveform modeling of teleseismic $P$ waves for Events 1, 2, 4, 5, 10, 11 and 16. Kao et al. (1998) compiled available solutions (including from the previous three studies),

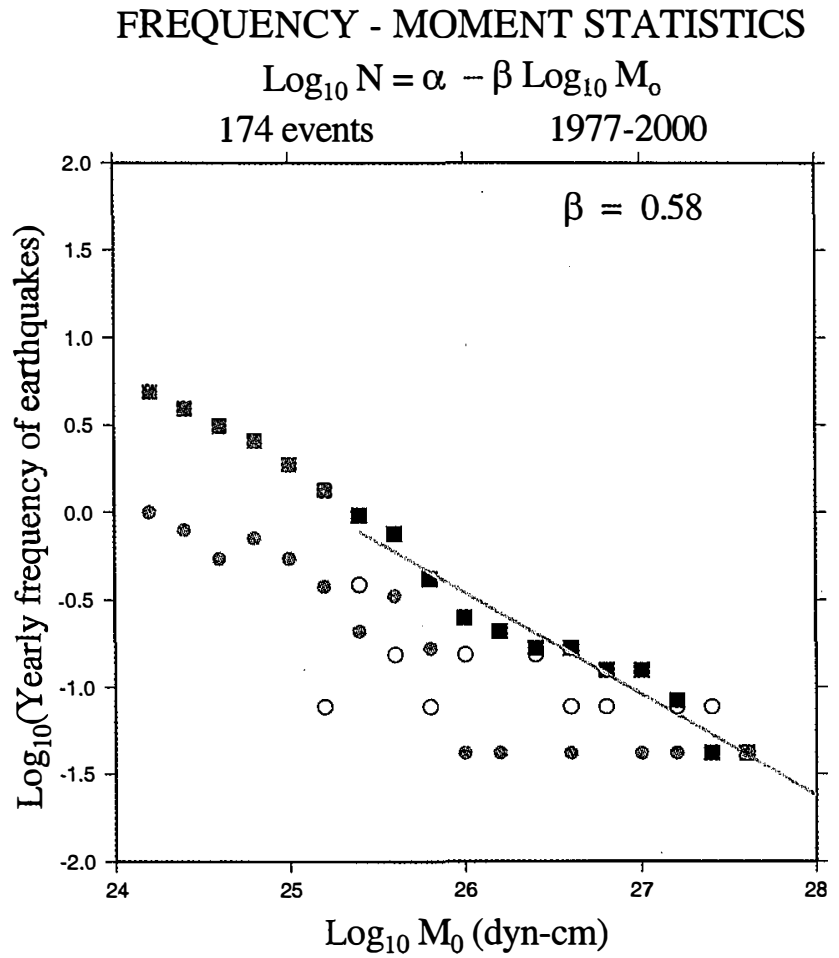

Fig. 4. Same as Fig. 3 for Taiwan earthquakes from the modern CMT catalog. The cumulative populations within the relevant range of moments (solid squares) yield a $\beta$ value of 0.58 . The open circles are from Fig. 3 for comparison. 
complemented by original waveform modeling for Events 6, 8, 12, 13 and 15. These focal mechanisms are shown as the smaller symbols on Fig. 5, and compared to our CMT solutions (larger symbols).

In Table 3, we quantify this comparison by forming, for each event, the logarithmic moment residual

$$
r=\log _{10} \frac{\left[M_{0}\right]^{p p}}{\left[M_{0}\right]^{C M T}},
$$

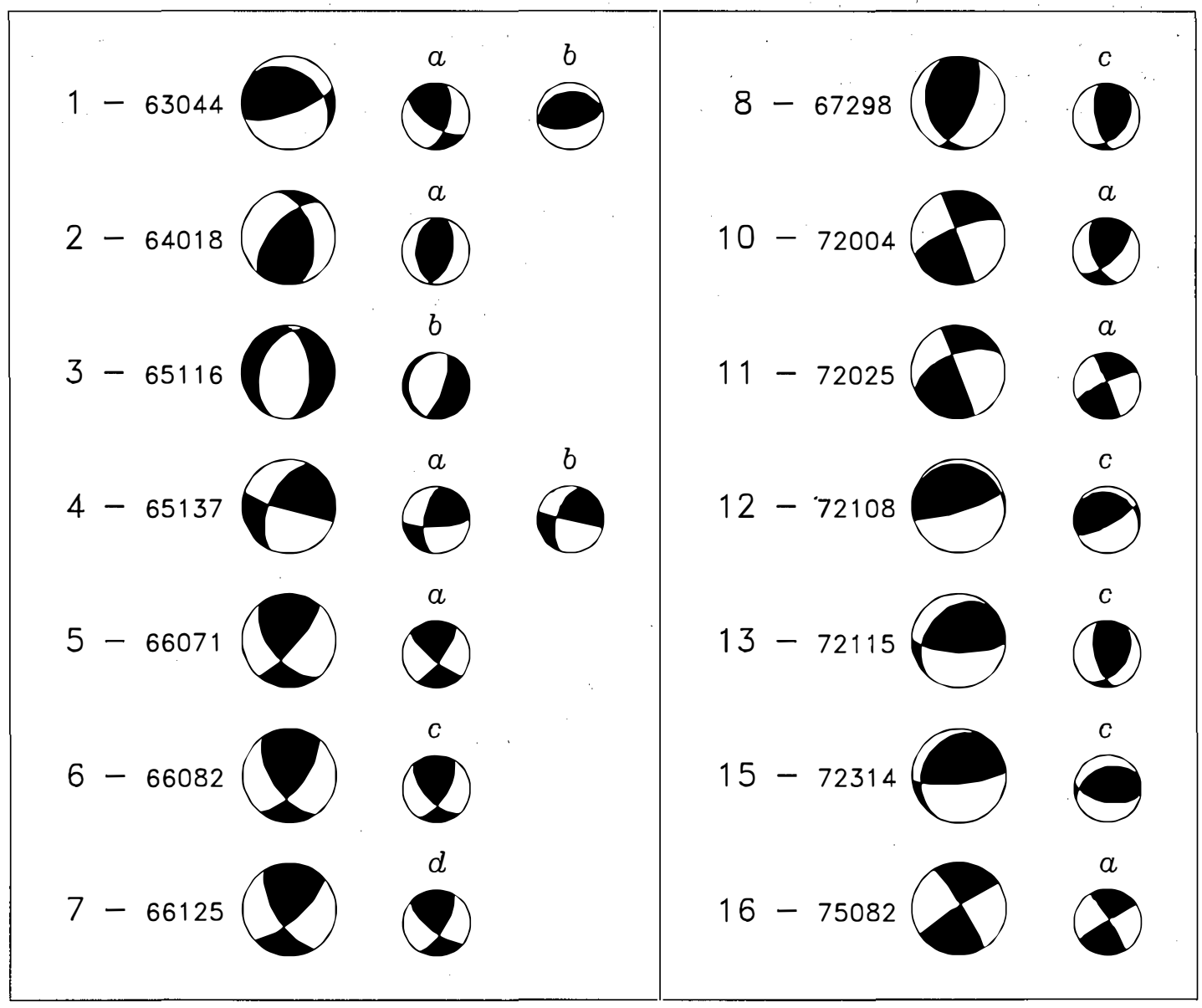

Fig. 5. Comparison of our CMT solutions (larger symbols) with previously published focal geometries (smaller symbols). The letters above the latter are keyed to the references in Table 3. 
Table 3. Comparison of our results with previously published solutions.

\begin{tabular}{|c|c|c|c|c|c|c|c|c|}
\hline \multirow{3}{*}{$\begin{array}{l}\text { Event } \\
\text { Number }\end{array}$} & \multirow{3}{*}{$\begin{array}{c}\text { Date } \\
\text { (YYJJJ) }\end{array}$} & \multicolumn{5}{|c|}{ Published Solution } & \multirow{3}{*}{$\begin{array}{c}\text { Logarithmic } \\
\text { Moment } \\
\text { Residual }\end{array}$} & \multirow{3}{*}{$\begin{array}{c}\text { Kagan Angle } \\
\Omega \\
\left({ }^{\circ}\right)\end{array}$} \\
\hline & & \multirow{2}{*}{$\begin{array}{c}M_{0} \\
\left(10^{25} \text { dyn-cm }\right)\end{array}$} & \multicolumn{3}{|c|}{ Focal geometry } & \multirow[t]{2}{*}{ Ref. } & & \\
\hline & & & $\phi\left({ }^{\circ}\right)$ & $\delta\left(^{\circ}\right)$ & $\lambda\left({ }^{\circ}\right)$ & & & \\
\hline 1 & 63044 & 100 & $\begin{array}{l}16 \\
79\end{array}$ & $\begin{array}{l}58 \\
61\end{array}$ & $\begin{array}{r}150 \\
90\end{array}$ & $\begin{array}{l}\mathrm{a} \\
\mathrm{b}\end{array}$ & 0.15 & $\begin{array}{l}68 \\
26\end{array}$ \\
\hline 2 & 64018 & 4 & 15 & 50 & 100 & a & -0.24 & 42 \\
\hline 3 & 65116 & & 186 & 18 & -102 & b & & 29 \\
\hline 4 & 65137 & 27 & $\begin{array}{l}188 \\
197\end{array}$ & $\begin{array}{l}60 \\
56\end{array}$ & $\begin{array}{r}20 \\
5\end{array}$ & $\begin{array}{l}\mathrm{a} \\
\mathrm{b}\end{array}$ & 0.35 & $\begin{array}{r}23 \\
7\end{array}$ \\
\hline 5 & 66071 & 486 & 130 & 76 & 18 & $\mathrm{a}$ & 0.27 & 23 \\
\hline 6 & 66082 & 2.75 & 31 & 63 & 147 & c & 0.02 & 10 \\
\hline 7 & 66125 & & 129 & 70 & 24 & d & & 22 \\
\hline 8 & 67298 & 20.5 & 37 & 37 & 132 & c & -0.05 & 8 \\
\hline 10 & 72004 & 11 & 158 & 56 & 33 & $\mathrm{a}$ & -0.36 & 61 \\
\hline 11 & 72025 & 134 & 336 & 86 & 10 & a & 0.01 & 22 \\
\hline 12 & 72108 & 1.44 & 62 & 77 & 74 & c & -0.39 & 13 \\
\hline 13 & 72115 & 16.4 & 36 & 41 & 132 & c & -0.33 & 74 \\
\hline 15 & 72314 & 1.25 & 100 & 57 & 109 & c & -0.11 & 25 \\
\hline 16 & 75082 & 28 & 328 & 84 & 3 & $\mathrm{a}$ & 0.41 & 3 \\
\hline
\end{tabular}

References: a: Pezzopane and Wesnousky (1989); b: Katsumata and Sykes (1969); c: Kao et al. (1998); d: Tsai et al.(1983)

[as defined by Huang and Okal (1998)], and the "Kagan angle" $\Omega$, defined as the angle of the minimum Euler rotation transforming the "beach ball" representation of the focal sphere of the best-fitting double-couple of our CMT solution into the published one (Kagan 1991). We recall that the maximum theoretical value of $\Omega$ is $120^{\circ}$. Several authors, notably Apperson and Frohlich (1992) and Kuge and Kawakatsu (1993) have proposed other methods of quantifying the disparity between two focal mechanisms, including sources featuring non-double-couple components. We prefer the concept of the Kagan angle on account of the simplicity of its geometric interpretation as a mere solid rotation.

While it may be futile to analyze statistically a dataset of only 12 values, we find that all measures of the population of residuals $r$ are comparable to their counterparts in Huang and Okal's (1998) study of deep earthquakes: the average residual $\langle r\rangle$ is a negligible -0.02 units, while the average of its absolute value, $\langle|r|>$ reaches 0.22 units, and the standard deviation $\sigma_{r} 0.27$ units. In addition, we find no significant correlation between $r$ (or $|r|$ ) and $M_{0}$ (Figs. $6 \mathrm{~b}, \mathrm{c})$.

Regarding focal geometry, we similarly fail to define a correlation between large Kagan angles and earthquake size (Fig. 6a), or between large $\Omega$ and large values of $r$ (or $|r|$; Figs. 6d, 
e). We discuss in detail the five events with large $\left(>40^{\circ}\right)$ Kagan angles between our solutions and previous ones.

Event 1. Julian Date (J.D.) 63044.

The large Kagan angle $\left(68^{\circ}\right)$ with respect to Pezzopane and Wesnousky's (1989) solution expresses substantial rotation of this mainly thrust mechanism. The CMT solution is much closer $\left(26^{\circ}\right)$ to Katsumata and Sykes' (1969), which essentially shares a focal plane, while
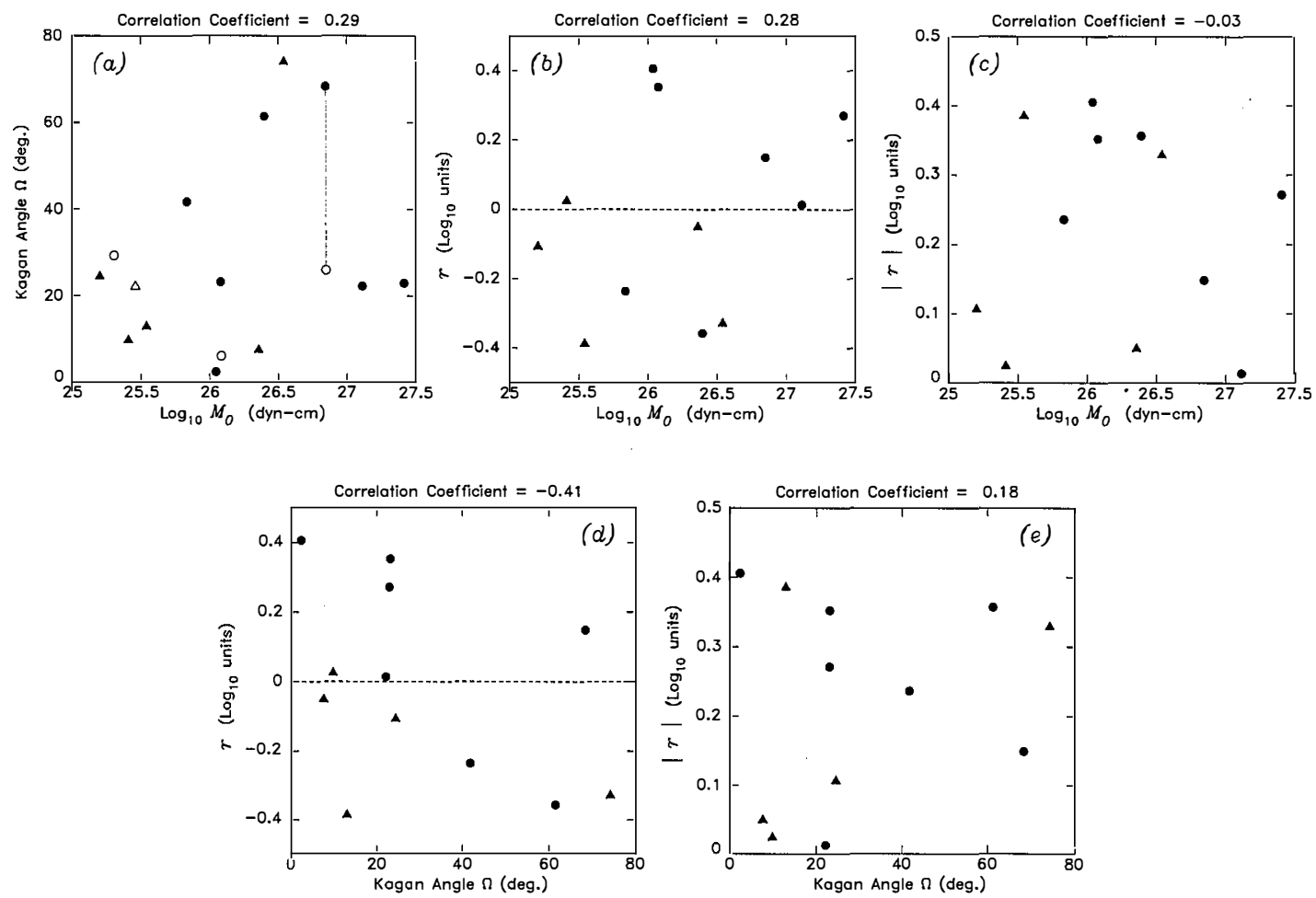

Fig. 6. (a) Kagan angles $\Omega$ between our solutions and previously published ones, plotted as a function of inverted seismic moment $M_{0}$. PP solutions are symbol-keyed as follows: solid circles: Pezzopane and Wesnousky (1989); open circles: Katsumata and Sykes (1969); solid triangles: Kao et al. (1998); open triangle: Tsai et al. (1983). The gray lines link solutions obtained from different PP sources for the same events. (b) Logarithmic moment residual $\mathrm{r}$ plotted vs. $M_{0}$; same conventions as in (a). (c) Same as (b) for the absolute value of $r$. (d) Logarithmic moment residual $r$ plotted vs. Kagan angle $\Omega$. (e) Same as (d) for the absolute value of r. In all cases, note the poor correlation between the various variables plotted. 
keeping the slip angle constrained to $90^{\circ}$. Our mechanism is also close to that of the neighboring Event $15\left(\Omega=43^{\circ}\right)$, and to the solution for J.D. $02090\left(\Omega=12^{\circ}\right)$. It does depart from the geometry of the large earthquake on J.D. $86318\left(\Omega=57^{\circ}\right)$.

\section{Event 2, J.D. 64018.}

This is our only solution on the Western coast of Taiwan. We note that the Kagan angle of $42^{\circ}$ between our solution and Pezzopane and Wesnousky's (1989) is entirely taken up by the $\mathrm{T}$ axis, while the $\mathrm{P}$ axes of the two solutions differ by only $14^{\circ}$. The earthquake has no immediate neighbors to which it could be compared in the modern CMT catalog.

\section{Event 10, J.D. 72004.}

There is a large discrepancy $\left(\Omega=61^{\circ}\right)$ between our strike-slip solution and Pezzopane and Wesnousky's (1989) thrust mechanism. We note that for this particular event, these authors modeled only the initial part of the $\mathrm{P}$ waveforms, in view of complexities that they attributed to water column reverberations (their Fig. A6). Our inversion, carried out at a longer period, most likely eliminates this problem, and converges on a solution in much better agreement with the neighboring focal mechanisms obtained in this study (Events 10,11, 16 and 17).

\section{Event 13, J.D. 72115.}

Our centroid solution locates inside the island of Taiwan, and the inverted mechanism is remarkably similar to that of Event $15,63 \mathrm{~km}$ to the $\operatorname{NNE}\left(\Omega=11^{\circ}\right.$ between them). By contrast, Kao et al.'s (1998) mechanism also features thrust faulting, but is substantially rotated $\left(\Omega=74^{\circ}\right.$ from ours). The $\mathrm{P}$ axis for our mechanism, striking $345^{\circ}$, is also more in line with the slip partitioning documented in the region than is Kao et al.'s, striking $277^{\circ}$.

\section{CONCLUSIONS}

We have inverted 17 new centroid moment tensor solutions of shallow earthquakes in the vicinity of Taiwan for the period 1963-1975. The moment release rate for the cumulative dataset inverted in the present study is approximately double that of the following years for which the Harvard dataset is available (excluding the 1999 Chi-Chi earthquake). In addition, we observe significant disparities between the geometry of some of our solutions and mechanisms previously published for the same events. Our solutions lead to greater homogeneity in the geometries of stress release on a regional scale, especially along the Eastern seaboard of Taiwan (Events 1,13 and 15) and offshore, along the western flank of the Gagua Ridge, where Events 10,11, 16 and 17 define a coherent pattern of strike-slip faulting. Finally, our new dataset confirms a $\beta$-value lower than the worldwide average for shallow earthquakes, indicative of a relative surplus of large earthquakes. By extending the time window of reliable CMT solutions, our study provides an improved quantification of seismic moment release in the neighborhood of Taiwan. 
Acknowledgments We are grateful to Don Helmberger for lending us the precious 1963 seismograms from the Caltech WWSSN collection. We thank two reviewers for helpful comments. This study was supported by the National Science Foundation, under grant EAR97-0652 at Northwestern and EAR-02-07608 at Harvard.

\section{REFERENCES}

Aki, K., and P. G. Richards, 1980: Quantitative Seismology, 2 vol., W.H. Freeman, San Francisco.

Apperson, D., and C. Frohlich, 1992: Earthquake focal mechanisms, moment tensors, and the consistency of seismic activity near plate boundaries. Tectonics, 11, 279-296.

Chen, P. F., 2002: Distribution, origin, and implications of seismic stress release in shallow and intermediate-depth subduction systems. Ph.D. Dissertation, Northwestern Univ., Evanston, IL.

Chen, P. F., M. Nettles, E. A. Okal, and G. Ekström, 2001: Centroid Moment Tensor solutions for intermediate-depth earthquakes of the WWSSN-HGLP era (1962-1975). Phys. Earth Planet. Inter., 124, 1-7.

Dziewonski, A. M., and J. H. Woodhouse, 1983: An experiment in systematic study of global seismicity: Centroid-moment tensor inversion for 201 moderate and large earthquakes of 1981. J. Geophys. Res., 88, 3247-3271.

Dziewonski, A.M., T. A. Chou, and J. H. Woodhouse, 1981: Determination of earthquake source parameters from waveform data for studies of global and regional seismicity. J. Geophys. Res., 86, 2825-2852.

Ekström, G., and M. Nettles, 1997: Calibration of the HGLP seismograph network and centroid moment tensor analysis of significant earthquakes of 1976. Phys. Earth Planet. Inter., 101, 219-243.

Huang, W. C., and E. A. Okal, 1998: Centroid moment tensor solutions for deep earthquakes predating the digital era: Discussion and inferences. Phys. Earth Planet. Inter., 106, 191-218.

Huang, W. C., G. Ekström, E. A. Okal and M. P. Salganik, 1994: Application of the CMT algorithm to analog recordings of deep earthquakes. Phys. Earth Planet. Inter., 83, 283-297.

Huang, W. C., E. A. Okal, G. Ekström, and M. P. Salganik, 1997: Centroid-Moment-Tensor solutions for deep earthquakes predating the digital era: The WWSSN dataset (19621976). Phys. Earth Planet. Inter., 99, 121-129.

Kagan, Y. Y., 1991: 3-D rotation of double-couple earthquake sources. Geophys. J. Intl., 106, 709-716.

Kao, H., S. J. Shen, and K. F. Ma, 1998: Transition from oblique subduction to collision: Earthquakes in the Southernmost Ryukyu arc-Taiwan region. J. Geophys. Res., 103, 7211-7229.

Katsumata, M., and L. R. Sykes, 1969: Seismicity and tectonics of the Western Pacific: IzuMariana-Caroline and Ryukyu-Taiwan regions. J. Geophys. Res., 74, 5923-5948. 
Kuge, K., and H. Kawakatsu, 1993: Significance of non-double-couple components of deep and intermediate-depth earthquakes: Implications from moment tensor inversions of long-period seismic waves. Phys. Earth Planet. Inter., 75, 243-266.

Molnar, P., 1979: Earthquake recurrence intervals and plate tectonics. Bull. Seismol. Soc. Amer., 69, 115-133.

Okal, E. A., 1992: Use of the mantle magnitude Mm for the reassessment of the seismic moment of historical earthquakes. I: Shallow events. Pure Appl. Geophys., 139, 17-57.

Okal, E. A., and S. H. Kirby, 1995: Frequency-moment distribution of deep earthquakes: Implications for the seismogenic zone at the bottom of slabs. Phys. Earth Planet. Inter., 92, 169-187.

Okal, E. A., and B. A. Romanowicz, 1994: On the variation of b-value with earthquake size. Phys. Earth Planet. Inter., 87, 55-76.

Pezzopane, S. K., and S. G. Wesnousky, 1989: Large earthquakes and crustal defcrmation near Taiwan. J. Geophys. Res., 94, 7250-7264.

Rundle, J. B., 1989: Derivation of the complete Gutenberg-Richter magnitude-frequency relation using the principle of scale invariance. J. Geophys. Res., 94, 12337-12342.

Tsai, C. S., M. D. Lin, and Y. B. Tsai, 1983: Relocation of the 12 March 1966 earthquake sequence in northeast Taiwan offshore. Open Rep. ASIES-CR8306, Inst. Earth Sci. Acad. Sinica, Taipei, Taiwan.

Woodhouse, J. H., and A. M. Dziewonski, 1984: Mapping the upper mantle: three-dimensional modelling of the Earth structure by inversion of seismic waveforms. J. Geophys. Res., 89, 5953-5986. 